\title{
Dosimetry and microdosimetry using LET spectrometer based on the track-etch detector: radiotherapy bremsstrahlung beam, onboard aircraft radiation field
}

\author{
I. JADRNÍČKOVÁ ${ }^{1,2}$, F. SPURNÝ ${ }^{1}$
}

(Manuscript received 29 June 2006, accepted 4 August 2006)

ABSTRACT The spectrometer of linear energy transfer (LET) based on the chemically etched polyallyldiglycolcarbonate (PADC) track-etch detector was developed several years ago in our institute. LET spectra are estimated through track parameters determination carried out by an automatic optical image analyzer LUCIA G. This LET spectrometer enables determining LET of particles approximately from 10 to $700 \mathrm{keV} / \mu \mathrm{m}$. From the LET spectra, dose characteristics can be calculated. This contribution presents the use of this spectrometer in some applications - studies in $18 \mathrm{MV}$ radiotherapy bremsstrahlung beam and investigation onboard a commercial aircraft during more than 6 months long exposure. The LET spectra obtained in both experiments represent mainly the contribution of secondary or tertiary particles created through the nuclear reactions of photons (bremsstrahlung beam) or neutrons and neutron-like reacting particles (onboard aircraft) in the detector itself or in the surroundings material. The dose due to the photoparticles represents about $3 \times 10^{-4}$ of the photon dose; for the dose equivalent this value is about $2 \times 10^{-3} \mathrm{~Sv} / \mathrm{Gv}$. Regarding the onboard aircraft exposure, the results obtained using LET spectrometer were compared with those achieved with other methods and a reasonable agreement were stated.

Keywords: linear energy transfer / bremsstrahlung beam / onboard aircraft / track etch detector

RÉSUMÉ Dosimétrie et micro-dosimétrie au moyen d'un spectromètre à transfert linéique d'énergie basé sur des détecteurs solides de traces : Mesure dans un faisceau de rayonnement $X$ de radiothérapie et du champ de rayonnement à bord d'avion.

Au cours des dernières années, nous avons développé, pour la mesure du transfert d'énergie linéique (TLE), un spectromètre basé sur des détecteurs solides de traces (polyallyldiglycolcarbonnate-PADC) attaqué chimiquement. La distribution du TLE est obtenue à partir des paramètres de traces déterminés avec un analyseur automatique d'image de type LUCIA G. Ce spectromètre permet de déterminer les spectres du TLE entre 10 et $700 \mathrm{keV} / \mu \mathrm{m}$. À partir de ces spectres, il est possible de calculer les caractéristiques dosimétriques. Ce travail présente les résultats obtenus avec ce spectromètre pour deux applications différentes : d'une part la mesure dans un faisceau de radiothérapie composé de rayonnement $X$ de $18 \mathrm{MV}$ et d'autre part la mesure du rayonnement cosmique à bord d'avion sur une période de six mois. Les spectres de TLE obtenus caractérisent la contribution. La dose secondaire due aux

1 Dept. of Radiation Dosimetry, Nuclear Physics Institute AS CR, Na Truhlářce 39/64, 18086 Prague 8, Czech Republic.

2 Dept. of Dosimetry and Application of Ionizing Radiation, Czech Technical University, Břehová 7, 11519 Prague 1, Czech Republic. 
neutrons dans le faisceau de radiothérapie est environ égale à $3 \times 10^{-4} \mathrm{~Gy}$ par $\mathrm{Gy}$ traitement, soit en terme d'équivalent de dose $2 \times 10^{-3} \mathrm{~Sv}$ par Gy traitement. Concernant les mesures réalisées à bord d'avion, les résultats obtenus avec le spectromètre sont comparés avec ceux obtenus par d'autres méthodes. Un accord raisonnable a pu être constaté.

\section{Introduction}

Risk from ionizing radiation depends both on the radiation quantity and also on the quality of radiation. The radiation quality can be characterized by the methods and procedures of microdosimetry. The tissue-equivalent proportional counters are probably one of the most used and the most accurate methods. However, in some cases their use can be compromised, for example at high dose rates and/or in the presence of very intense low LET component in the radiation field to be characterized. Therefore the method of LET spectrometer based on a polyallyldiglycolcarbonate (PADC) chemically etched track-etch detectors was developed at the Nuclear Physics Institute, AS CR (Charvát, 1986). The track detectors have some advantages in comparison to other microdosimetry methods, especially in situations where dimensions and weight of detectors are important, high-LET particles have to be characterized in low-LET intense radiation beams and fields, or long exposure time is expected. For these reasons, this spectrometer may be used onboard aircraft and spacecraft to specify the radiation fields or to determine dosimetric and microdosimetric characteristics in the radiotherapeutic beams; these are the studies that we pursue in this paper.

The experiment in the radiotherapy bremsstrahlung beam with primary energy of $18 \mathrm{MV}$ was performed with the goal to determine the contribution of secondary or tertiary particles created in photonuclear reactions to the dose. Photons with sufficiently high energy ( $>10 \mathrm{MeV}$ ) (IAEA, 1987) can produce particles with higher values of LET in photonuclear reactions. The type and the energy of the photonuclear particles depend not only on the primary photon energy (generally with increasing photon energy the production of photonuclear high-LET particle increases) but also on the surrounding materials or on the medium in which photons interact. In direct photonuclear reactions mostly protons and neutrons are created but partially also alpha particles or light nuclei (tritons and ${ }^{3} \mathrm{He}$ have higher energy threshold, above $20 \mathrm{MeV}$ ) (Chibani and Ma, 2003). The importance of these particles consists in the fact that they can contribute to the dose in a patient; they may also have enhanced radiobiological effectiveness and so they represent radiation protection problem.

The second study concerns the dosimetry onboard a commercial aircraft during more than 6 months long exposure. Dosimetry onboard aircraft and spacecraft 
represents radiation protection problem since aircraft crew is exposed to cosmic radiation during flights. Note that Publication 60 of ICRP (1991) recommends checking the exposure of the aircrew. The radiation field induced by solar and galactic cosmic radiation is complex; it consists of a broad spectrum of different particles. These particles can be divided into low-LET component (mostly electrons, high-energy protons, and photons) and high-LET component (neutrons and neutron-like reacting particle) (Bartlett et al., 1997). The high-LET component can be determined by means of the LET spectrometer; the results are also compared to those obtained with other methods (LIULIN spectrodosimeter, neutron track etch detector, transport calculation code).

\section{Material and methods}

\subsection{Spectrometer of linear energy transfer}

The spectrometer of linear energy transfer (LET) is based on the chemically etched polyallyldiglycolcarbonate (PADC) track-etch detector. In the studies, two types of the material were used: Page (Page Moulgings Ltd, England) and Tastrak (Track Analysis Systems Ltd, Bristol), both with a thickness of $0.5 \mathrm{~mm}$. Before etching, one corner of each sample used is irradiated with ${ }^{252} \mathrm{Cf}$ fission fragments and another one with alpha particles from ${ }^{241} \mathrm{Am}$ to check the exact etching conditions. After irradiation, the detectors are etched in $5 \mathrm{~N} \mathrm{NaOH}$ at $70{ }^{\circ} \mathrm{C}$ during 18 hours, which corresponds to the removal of a layer about $17 \mu \mathrm{m}$ thick on each side of the detector. To determine the LET value of a particle, the etching rate ratio $\mathrm{V}$ ( $\mathrm{V}=$ $\mathrm{v}_{\mathrm{T}} / \mathrm{v}_{\mathrm{B}}$; where $\mathrm{v}_{\mathrm{B}}$ is bulk etching rate and $\mathrm{v}_{\mathrm{T}}$ is track etching rate) is established through the determination of track parameters. They are measured by means of an automatic optical image analyzer LUCIA G. The obtained V-spectra are then transformed into the LET spectra using the calibration curves. The calibration was performed during several last years in high energy heavy charged particle beams with LET in water from about 7 to about $600 \mathrm{keV} / \mu \mathrm{m}$, partly at HIMAC installation (NIRS Chiba, Japan) and partly at the Nuclotron (JINR, Dubna). This LET spectrometer enables determining LET of particles approximately from 10 to $700 \mathrm{keV} / \mu \mathrm{m}$ (Spurný et al., 1996a, 2004, 2005). The absorbed dose and dose equivalent can be calculated from the LET spectra:

$$
\begin{gathered}
D_{L E T}=(d N / d L) L d L, \\
H_{L E T}=(d N / d L) L Q(L) d L,
\end{gathered}
$$

where $d N / d L$ is the number of tracks in the interval $d L, L$ is the LET of a particle, and $Q(L)$ is the Publication 60 of ICRP quality factor (ICRP, 1991). 


\subsection{Radiotherapy bremsstrahlung beam}

The experiment was performed in the radiotherapy bremsstrahlung beam from linac (type Varian) with primary energy $18 \mathrm{MV}$ at the hospital $\mathrm{Na}$ Bulovce (Prague, Czech Republic) during two runs. The detectors were exposed in the maximum of the depth-dose distribution, at the therapeutic bremsstrahlung dose $20 \mathrm{~Gy}$. The dose measurements and monitoring were assured by the hospital staff.

\subsection{Onboard aircraft}

The detectors were exposed from May 2005 to January 2006 (for 242 days) onboard the commercial aircraft of Czech Airlines. They were all time fixed on the surface of MDU-LIULIN Si-spectrodosimeter (Spurný and Dachev, 2003). 504 individual flights were realized during all period mentioned. Colleagues from Czech Airlines submitted us for each individual flight full navigation data, i.e. geographic latitude and longitude, pressure corrected flight altitude specified for universal time with 5 minutes interval. These data permitted us to calculate the doses onboard aircraft by means of calculation code EPCARD (Schraube et al., 1992).

\section{Results and discussion}

\subsection{Radiotherapy bremsstrahlung beam}

After the irradiation, the detectors were evaluated to obtain the LET spectra. Because the track-etch detectors are insensitive to photons up to the dose of $10^{4} \mathrm{~Gy}$, the observed tracks correspond to the secondary or tertiary particles with LET above the registration threshold (about $7 \mathrm{keV} / \mu \mathrm{m}$ for Page and $15 \mathrm{keV} / \mu \mathrm{m}$ for Tastrak) produced through the photonuclear reactions in the detectors or in the surrounding materials. Typical LET spectra of absorbed dose and dose equivalent in the form of microdosimetry distributions $(D(L) \times L$ and $H(L) \times L)$ are presented in Figures 1 and 2. For the dose distribution there are not negligible differences between both materials, whereas both distributions are quite similar in the case of dose equivalent distribution.

The integral absorbed doses and dose equivalents due to the registered photonuclear particles were calculated from the LET spectra using equations (1) and (2). It is necessary to notice that both the absorbed doses and dose equivalents are only due to the particles with LET higher than the detection thresholds for individual materials. These particles represents $(2.8 \pm 0.5) \times 10^{-4}$ of the photon dose (for both material); in case of dose equivalent this value is $(1.9 \pm 0.3) \times 10^{-3}$ for Page and $(2.2 \pm 0.3) \times 10^{-3}$ for Tastrak, respectively. 
DOSIMETRY AND MICRODOSIMETRY USING LET SPECTROMETER

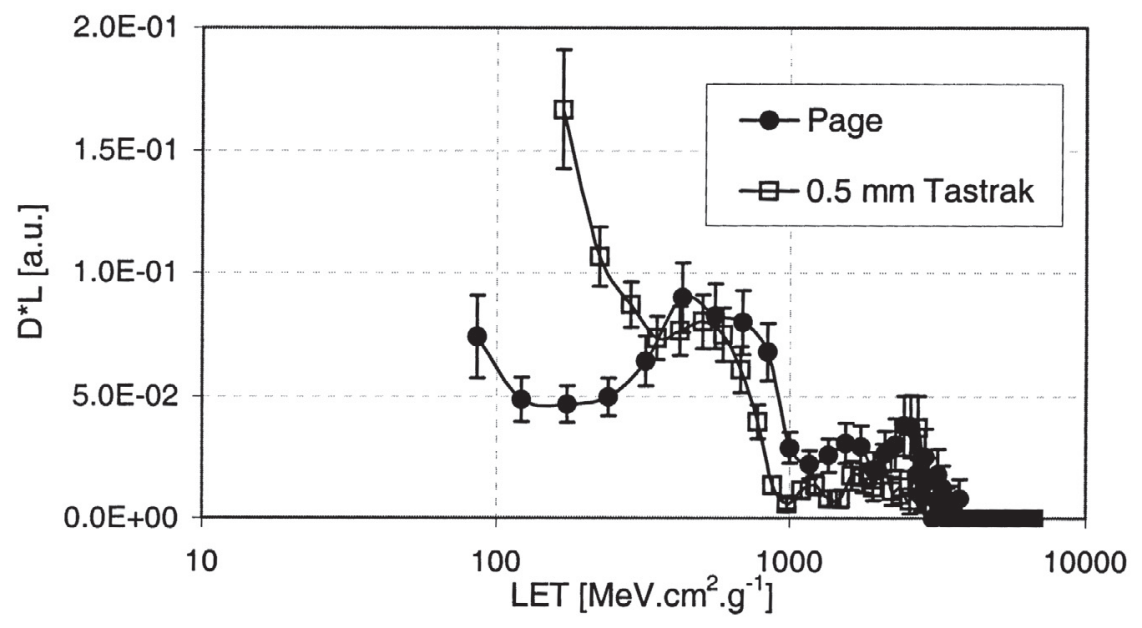

Figure 1 - Microdosimetry distributions of absorbed dose - $18 \mathrm{MV}$ bremsstrahlung beam.

Distribution micro-dosimétrique de la dose absorbée dans le faisceau de rayonnement $\mathrm{X}$ de $18 \mathrm{MV}$.

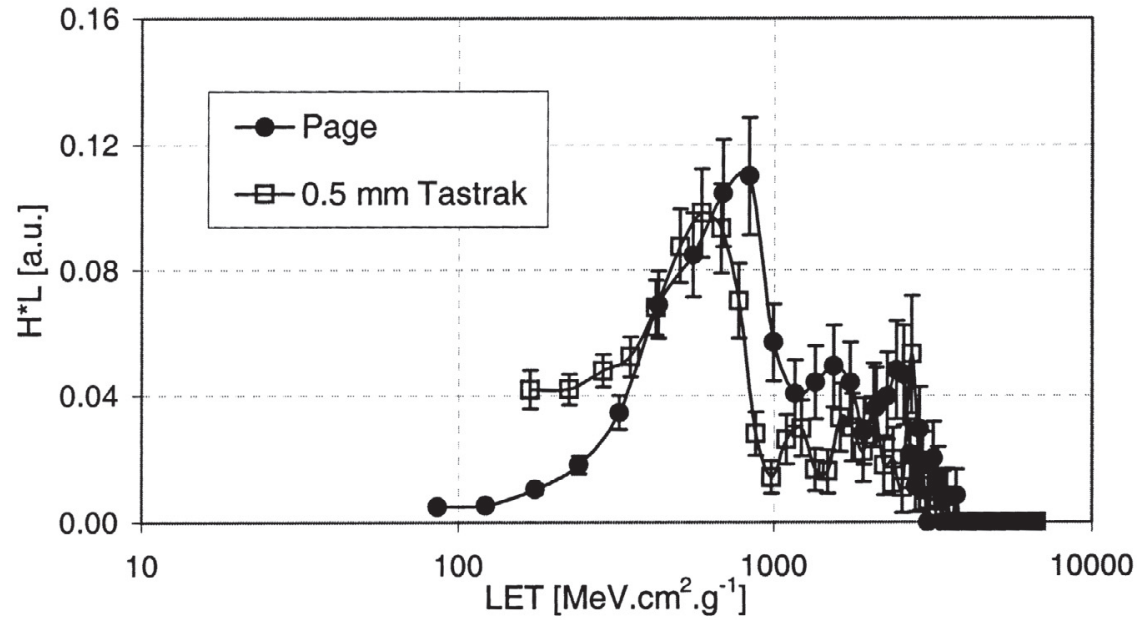

Figure 2-Microdosimetry distributions of dose equivalent - 18 MV bremsstrahlung beam.

Distribution micro-dosimétrique de l'équivalent de dose dans le faisceau de rayonnement X de $18 \mathrm{MV}$. 
Absorbed dose due to the photonuclear particles in a tissue irradiated with various energies of photons has been directly investigated in the past. Allen and Chaudhri (1988) calculated that the total integral absorbed dose to the tissue due to all photonuclear reactions for $24 \mathrm{MeV}$ bremsstrahlung beam is $0.08 \%$ of the photon dose and the integral dose equivalent is $1.1 \%$ of the photon dose. These values are higher than those determined in our work. Except that the energy in our experiment is lower, another reason may be the fact that the track detectors measure only particles with LET higher than the registration threshold, but the contribution of low-LET particles may be high. Spurný et al. (1996b) evaluated the high-LET photonuclear dose in $20 \mathrm{MV}$ bremsstrahlung beam to be about $0.04 \%$ of the photon dose, which value is close to the one determined by us. However, it is very difficult to compare the results obtained by various authors because of different bremsstrahlung beam spectra, different geometries (accelerator design and phantom), and different techniques used to estimate the absorbed dose.

\subsection{Onboard aircraft}

Also in this case, the tracks registered in the LET spectrometer onboard aircrafts correspond mostly to the secondary and tertiary particles (with LET above the registration threshold) produced through nuclear reactions of neutrons and, partially, neutron-like interacting particles. The example of microdosimetry distribution of dose equivalent are presented in Figure 3 (for Page) and in Figure 4 (for Tastrak). The uncertainties of the measured dose equivalent for higher LET are quite high - this is due to the fact that there are only few tracks and so the statistical uncertainties are rather high.

The results measured with the LET spectrometer are summarized in Table I where they are compared with the results obtained for neutron and neutron-like component by other, independent methods - MDU-LIULIN Si-spectrodosimeter, track etch neutron detector (Turek et al., 1993), EPCARD code. The values obtained with LET spectrometer could be considered as slightly lower, it could be related to the fact that some of neutron induced secondary charged particles have LET lower than thresholds mentioned. However, the differences are comparable to the extent of uncertainties.

\section{Conclusions}

The spectrometer of LET was used to determine the dosimetric characteristics and the LET spectra in the $18 \mathrm{MV}$ radiotherapy bremsstrahlung beam and onboard the commercial aircraft. The secondary heavy charged particles in the radiotherapy 
DOSIMETRY AND MICRODOSIMETRY USING LET SPECTROMETER

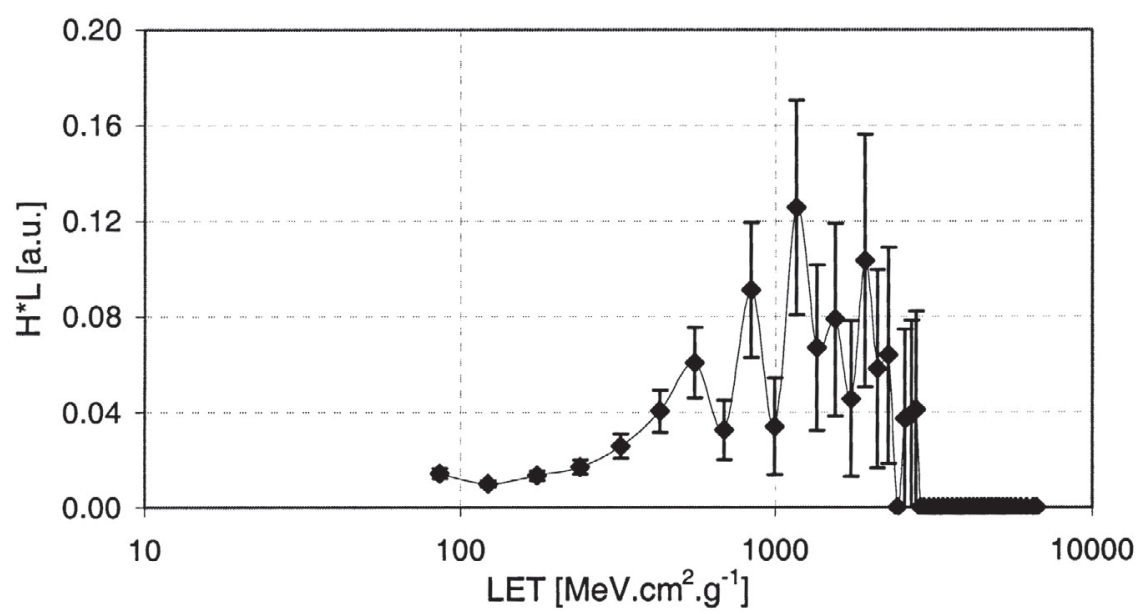

Figure 3 - Microdosimetry distributions of dose equivalent onboard aircraft-detector Page. Distribution micro-dosimétrique de l'équivalent de dose mesuré à bord d'avion - détecteur Page.

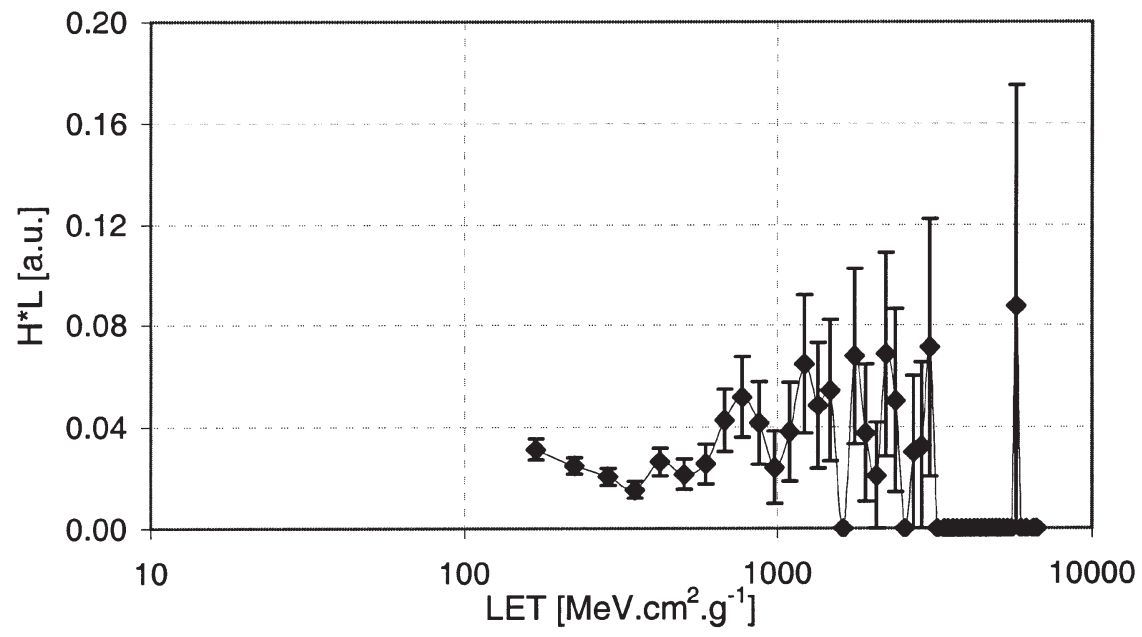

Figure 4 - Microdosimetry distributions of dose equivalent onboard aircraft - detector Tastrak.

Distribution micro-dosimétrique de l'équivalent de dose mesuré à bord d'avion - détecteur Tastrak. 


\section{TABLE I}

Integral values of dosimetric quantities for onboard aircraft neutron component during a long term monitoring of exposure.

Valeurs intégrées des quantités dosimétriques dues à la composante neutronique à bord d'avion pour une exposition de longue durée.

\begin{tabular}{ccc}
\hline Method & Quantity & Integral value [mSv] \\
\hline LET spectrometer - Page & $H^{*}(10)$ & $3.5 \pm 1.4$ \\
LET spectrometer - Tastrak & $H^{*}(10)$ & $4.2 \pm 1.2$ \\
${\text { Track etch neutron dosimeter - I }{ }^{1)}}$ Track etch neutron dosimeter - II $^{1)}$ & $H^{*}(10)$ & $4.1 \pm 0.7$ \\
EPCARD - calculated & $H^{*}(10)$ & $6.3 \pm 0.8$ \\
MDU-LIULIN Si-spectrodosimeter & $H^{*}(10)$ & 5.72 \\
\hline${ }^{1)}$ I - chemical etching followed by high frequency electrochemical etching, II - two frequence electrochemical
\end{tabular}
etching (Turek et al., 1993).

beam are mainly composed by the particles with LET below $100 \mathrm{keV} / \mu \mathrm{m}$. The dose due to the high-LET secondary particles represents $(2.8 \pm 0.7) \times 10^{-4}$ of the radiotherapeutic dose; for the dose equivalent this value is $(2.1 \pm 0.4) \times 10^{-3}$. As far as the onboard aircraft exposure is concerned the values of $H^{*}(10)$ established for neutron and neutron-like component are in reasonable agreement with the data obtained by other experimental methods and by calculation. They correspond in average to about $1.5-2.5 \mu \mathrm{Sv}$ per hour ambient dose equivalent on the altitude, according to used methodology.

\section{REFERENCES}

Allen P.D., Chaudhri M.A. (1988) Photoneutron production and dosimetry in tissue during high energy bremsstrahlung radiotherapy, Rad. Prot. Dos. 23, 341-344.

Bartlett D.T., McAulay I.R., Schrewe U.J., Schnuer K., Menzel H.G., Bottollier-Depois J.-F., Dietze G., Gmür K., Grillmaier R.E., Heinrich W., Lim T., Lindborg L., Reitz G., Schraube H., Spurný F., Tommasino L. (1997) Dosimetry for occupational exposure to cosmic radiation, Rad. Prot. Dos. 70, 395-404.

Charvát J. (1986) LET spectrometry with polymer SSNTD's, Ph.D. thesis, University of Prague, 1986.

Chibani O., Ma C.-M.C. (2003) Photonuclear dose calculations for high-energy photon beams from Siemens and Varian linacs, Med. Phys. 30, 1900-2000.

IAEA (1987) Absorbed dose determination in photon and electron beams: an International Code of Practice, IAEA Technical Reports Series 277, IAEA, Vienna.

ICRP Publication 60 (1991) 1990 Recommendations of the Internal Commission on Radiological Protection. Oxford, Pergamon Press.

Schraube H., Leuthold G., Heinrich W., Roessler S., Mareš V., Schraube G. (1992) European program package for the calculation of aviation route doses - User's manual, GSF-National Research Center on Environmental and Health. 


\section{DOSIMETRY AND MICRODOSIMETRY USING LET SPECTROMETER}

Spurný F., Bednáŕ J., Johansson L., Sätherberg A. (1996a) LET spectra of secondary particles in CR 39 track etch detectors, Radiat. Meas. 26, 645-649.

Spurný F., Johansson L., Sätherberg A., Bednár J., Turek K. (1996b) The contribution of secondary heavy particles to the absorbed dose from high-energy photon beams, Phys. Med. Biol. 41, 26432656.

Spurný F., Dachev Ts. (2003) Long-term monitoring of the onboard aircraft exposure level with a Sidiode based spectrometer, Adv. Space Res. 32, 53-58.

Spurný F., Molokanov A.G., Bamblevski V.P. (2004) Spectrometry of linear energy transfer, its development and use, Rad. Prot. Dos. 110, 675-679.

Spurný F., Jadrníčková I., Molokanov A.G., Bamblevski V.P. (2005) Upgrading of LET track-etch spectrometer: Calibration and uncertainty analysis, Radiat. Meas. 40, 343-346.

Turek K., Spurný F., Alberts W.G. (1993) On the optimization of the etching of CR39 as fast neutron dosimeter, Nucl. Tracks Radiat. Measur. 21, 299-302. 